\title{
Nueva célula 'en cepillo' (brush cell) o célula monopolar del cerebelo. Características y posible función
}

\author{
M.I. Álvarez-Vicente ${ }^{\text {a }}$, M. Lloréns-Martín ${ }^{\text {a }}$ C. Lacruz-Pelea ${ }^{\text {b }}$, A. Toledano-Gasca ${ }^{\text {a }}$
}

\author{
A NEW CEREBELLAR NEURON: THE BRUSH OR MONOPOLAR CELL. \\ CHARACTERISTICS AND POSSIBLE FUNCTION
}

\begin{abstract}
Summary. The basic neuronal structure and circuitry of the cerebellum has been well known since Cajal's time. In recent years, however, a number of new neuronal connections and new immunohistochemically-defined neuronal subtypes and functional cerebellar modules have been described. This new morphofunctional concept of the cerebellum seems to be in agreement with its newly assumed roles in learning and memory. In this new functional structure, a new cell (the brush cell, monopolar cell or monodendritic cell, Altman and Bayer, 1977; Mugnaini, 1994) specific to the cerebellar cortex and cochlear nucleus, could be of great importance. In all species studied, including man, this cell shows very particular morphology, immunohistochemical reactivity (against calretinine, some glutamate receptors and some neurofilament antibodies) and synaptic connections. The main afferents of these neurons are the mossy fibres, which form giant synaptic structures with them. The axons of monopolar cells end either in contact with extracerebellar neurons, or terminate intracortically at other brush cells (in the form of mossy fibres) or other cortical neurons of still-unknown morphology. In every animal species examined, these monopolar cells show different embryological development. No involution of them has been seen either in senility or in neurodegenerative disease. [REV NEUROL 2004; 38: 339-346]
\end{abstract}

Key words. Brush cells. Calretinin. Cerebellum. Monopolar cells. Pale cells.

\section{INTRODUCCIÓN}

La corteza cerebelosa se ha estudiado ampliamente, y descrito a la perfección en su organización básica, desde la época de Santiago Ramón y Cajal (1911) [1], caracterizándose por su aparente sencillez citoarquitectónica, debido al reducido número de tipos neuronales que establecen unos circuitos muy preciosos $\mathrm{y}$ repetitivos (Fig. 1a). Posteriormente, diversos estudios han mostrado la existencia de algún nuevo tipo celular -como las células de Lugaro- y de algunos nuevos tipos de conexiones - como las conexiones colaterales de muchas fibras aferentes y eferentes y las sinapsis 'en marrón' entre algunas fibras musgosas (FM) y células de Golgi-, que son poco frecuentes y repetitivas, pero que se integran constantemente en la estructura de todas las regiones del cerebelo y complican nuestra concepción del mismo (Fig. 1b). En los últimos años se ha descrito una nueva célula, denominada 'monopolar', 'monodendrítica', o 'en cepillo' (célula brush), cuyas conexiones todavía se desconocen bastante, pero a la que se puede asignar próximamente algún importante papel; podría ser la base de determinadas nuevas funciones de aprendizaje, memoria y coordinación que se le han adjudicado recientemente al cerebelo y que parecen tener cada vez más importancia para comprender distintas funciones cognitivas del cerebro [2-8]. Asimismo, estas células podrían ser claves para diferenciar o conectar los 'módulos' morfofuncionales cerebelosos, que también se describen con ayuda de determinados marcadores histoquímicos, como la zebrina, la neurogranina o la motilina [9-14].

Recibido: 01.12.03. Aceptado tras revisión externa sin modificaciones: 14.01.04.

${ }^{a}$ Laboratorio de Involución. Instituto Cajal. CSIC. ${ }^{b}$ Departamento de Anatomía Patológica. Hospital General Universitario Gregorio Marañón. Madrid, España.

Correspondencia: Dr. Adolfo Toledano Gasca. Instituto Cajal. Avda. Doctor Arce, 37.E-28002 Madrid.Fax: +34915854 754.E-mail: atoledano@ cajal.csic.es

(c) 2004, REVISTA DE NEUROLOGÍA
Este trabajo constituye una revisión de los conocimientos que actualmente se tienen de las células monodendríticas o 'en cepillo' (CEC).

\section{ANTECEDENTES}

El nombre de células 'en cepillo' (brush cells) o de células monodendríticas lo empleó por primera vez Munoz en 1990 [15], tras diferenciar esta nueva tipología celular en un estudio sobre inmunorreactividad frente a cromogranina A. Pero fue Mugnaini, en 1994 [16], quien, en un estudio realizado en distintos mamíferos (rata, ratón, gato y mono) y con el empleo de una variante del método de Golgi, realizó la primera descripción de estas células. Previamente a estos trabajos, Altman y Bayer, en 1977 [17], describieron unos cuerpos neuronales localizados en la capa granular de la rata, de un tamaño intermedio, a los que denominaron 'células pálidas' (pale cells), por presentar, en secciones teñidas con hematoxilina-eosina, núcleos pálidos, débilmente teñidos, perfectamente distinguibles de los de otras células de la capa granular. Estas células presentaban una localización y una distribución semejante a las CEC descritas por Mugnaini. Las CEC se han observado en distintas especies de mamíferos, incluido el hombre (rata, ratón, cobaya, mono, conejo, gato), aves y quelonios [15,18-20], y presentaban características comunes en todos ellos.

\section{Características al microscopio óptico}

Las CEC se pueden observar al microscopio óptico con el empleo de diversos métodos, entre los que cabe destacar las impregnaciones metálicas, como el método Golgi, y las reacciones inmunocitoquímicas.

Las CEC se localizan exclusivamente en el cerebelo [16] y en los núcleos cocleares [21-24], si bien en esta última localización existen algunas diferencias significativas del contenido de macromoléculas en primates. En el cerebelo tienen su mayor densidad en el vermis, preferentemente en la capa granular, por debajo de las neuronas de Purkinje (Fig. 2a), aunque ocasional- 


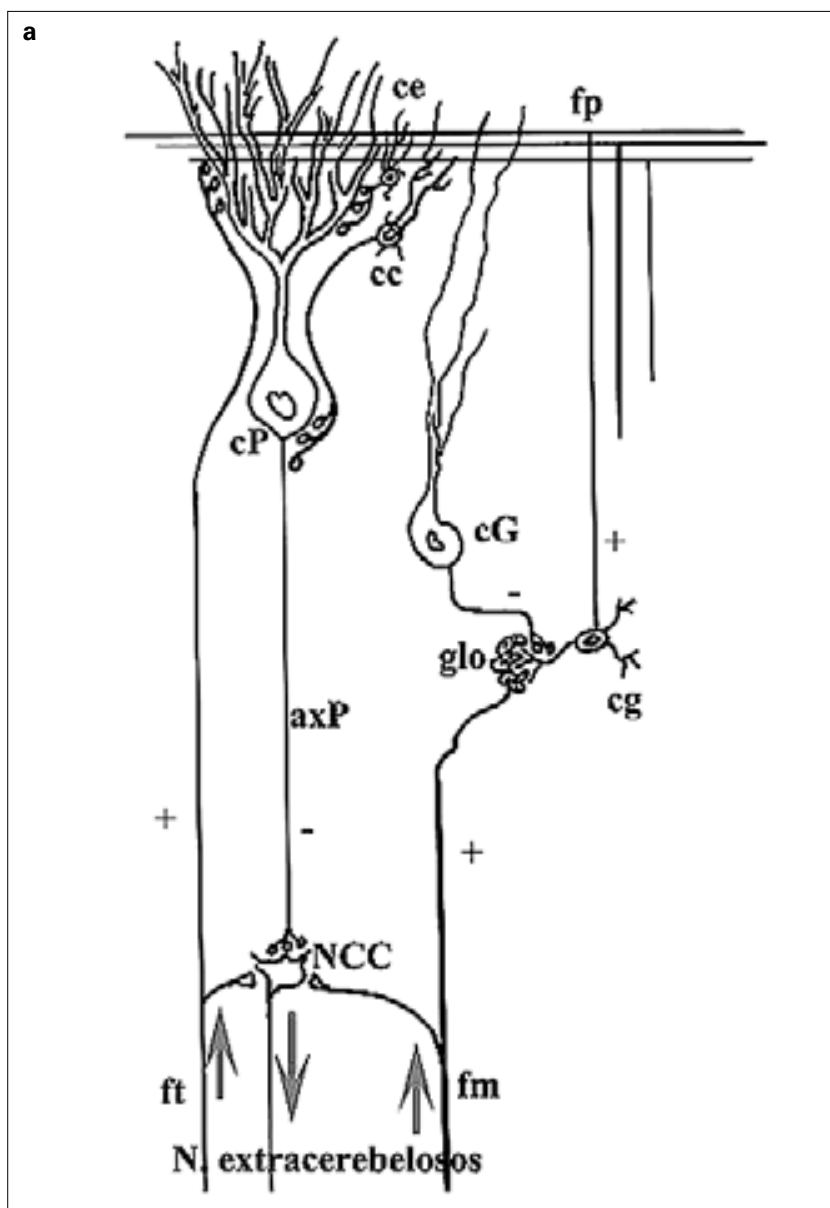

Figura 1. Circuitos cerebelosos. a) Circuito básico. La corteza recibe las fibras musgosas (fm), que forman los glomérulos cerebelosos ( $\mathrm{glo}$ ), y las fibras trepadoras (ft), que estimulan las células grano y de Purkinje, respectivamente. Las células granos activan las células de Purkinje, salida inhibitoria de la corteza sobre los núcleos cerebelosos centrales, y también células inhibidoras intracorticales reguladoras de los glomérulos (células Golgi, cG) y de las células de Purkinje -células estrelladas (ce) y de los cestos (cc)-; b) Circuito ampliado con la inclusión de un nuevo elemento, las células de Lugaro (cL), de conexiones no bien conocidas, y de otros sistemas de conexiones homogéneamente no repetitivos, como las conexiones de los colaterales de las células de Purkinje (caxP) que conectan con todas las neuronas corticales, colaterales de musgosas que forman sinapsis ('en marrón') con células de Golgi (cG/fm) y colaterales de $\mathrm{ft}$ que forman contactos similares a las musgosas (cft); c) Circuito ampliado con la inclusión en la red de las células en cepillo (CEC). Se muestra una CEC principal (CEC activada por una terminal musgosa) cuyo axón puede salir directamente al exterior del cerebelo, dar origen a 'cadenas' de CEC (con conexiones 'musgosas'), o formar glomérulos convencionales oft.

les de alta y baja densidad [25]. Los lóbulos IX (úvula) y X (nódulo) y flóculo son los que presentan una mayor densidad celular (745 células $/ \mathrm{mm}^{3}$ en el lóbulo $\mathrm{X}$ de las ratas) y algo menor en el paraflóculo y lígula [20].

Estas células presentan una morfología celular constante entre las especies, con un cuerpo ovalado o redondeado, de un diámetro entre 9-12 $\mu \mathrm{m}$-un tamaño intermedio entre las células de Golgi $(9-23 \mu \mathrm{m})$ y las células grano $(6-7 \mu \mathrm{m})$ - y un núcleo pálido con cromatina homogéneamente distribuida, sin condensaciones y con nuceolo débilmente teñido. Tienen un único axón de 0,3-0,5 $\mu \mathrm{m}$ de diámetro, que suele salir de la parte inferior del soma celular, aunque, en algunas ocasiones, lo hace cerca de la dendrita. A una distancia entre 100 y $300 \mu \mathrm{m}$ del punto
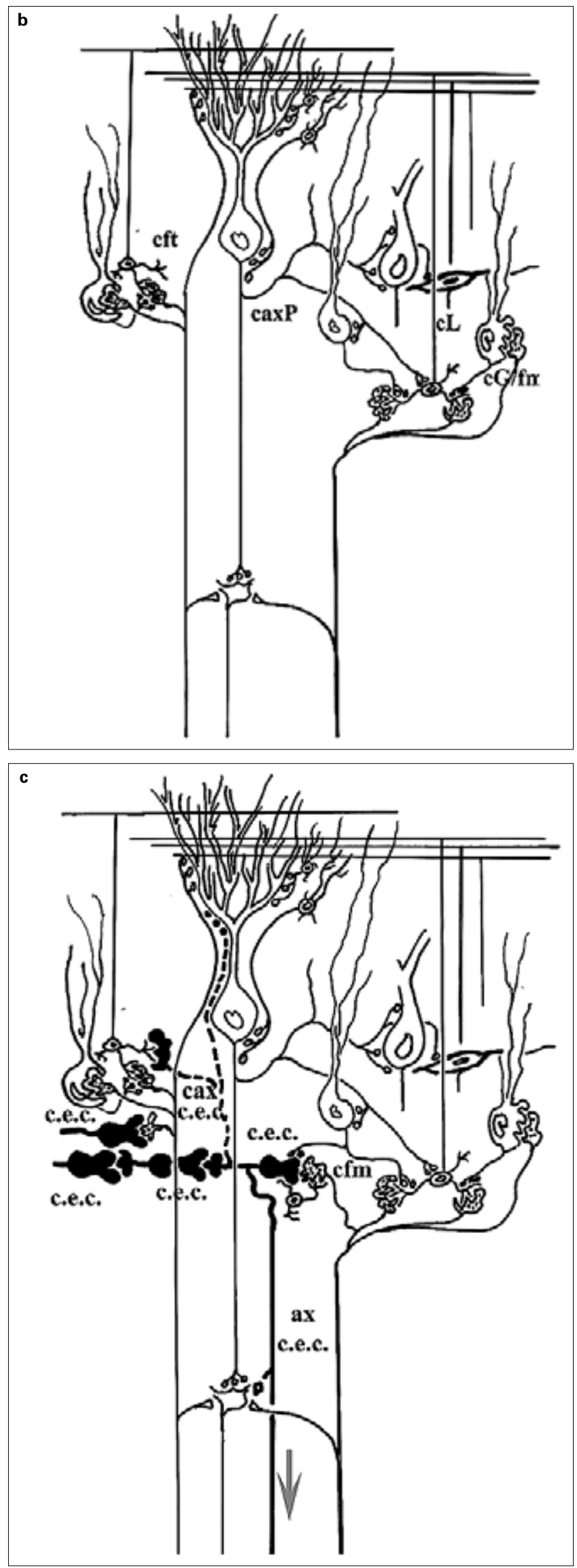

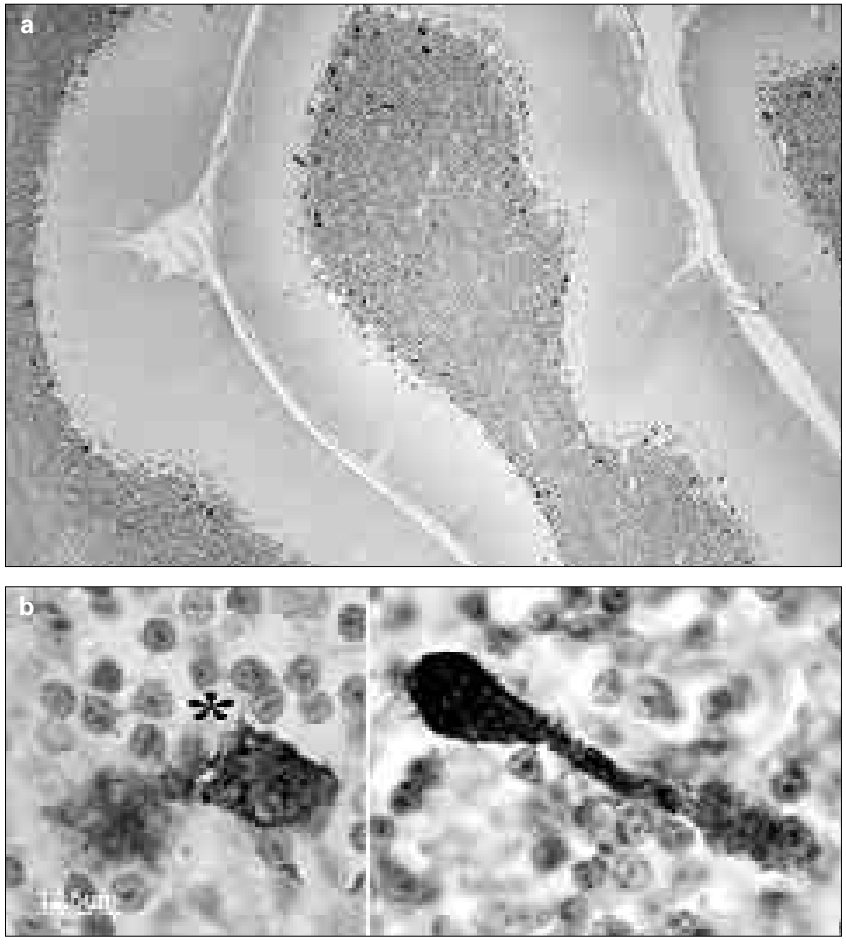

Figura 2. Cerebelo humano, lóbulo VI, inmunoteñido con anticalretinina. Más del $90 \%$ de las células positivas son CEC. a) Se puede observar su localización preferente en la capa granular, especialmente en la zona próxima a la capa de células de Purkinje. Existe mayor densidad celular en la cresta de las folias y no presentan ningún patrón de distribución espacial, y varía enormemente su número de folia a folia. b-c). Detalle de dos CEC, donde se puede observar el soma celular y dos tallos dendríticos acabados en cepillo de distinta longitud, uno corto (b) y otro largo (c). Espina somática típica de la CEC $\left({ }^{*}\right)$.

de inicio, muchos axones parece que se mielinizan y que salen de la corteza y del cerebelo. La diana principal del axón se desconoce todavía, aunque se cree que para un grupo importante de CEC localizadas en el arquicerebelo, su destino está en los núcleos vestibulares [16]. Otras CEC podrían tener sus terminaciones intracorticalmente, en la capa de los granos -como FMo en la capa molecular -como fibras trepadoras-(Fig. 1c). El recorrido de los axones a través de la capa de los granos es tortuoso, e incluye un primer tramo que se dirige hacia la sustancia blanca, para volver hacia la capa granular, y puede hacerlo hacia el mismo lado o hacia el lado contrario de la folia, donde se encuentra el origen. En ocasiones, presentan varios axones colaterales caracterizados, al igual que el axón principal, por drásticas variaciones de diámetro a lo largo de su recorrido. A menudo, en sus terminaciones aparecen unas excrecencias a modo de rosetas que recuerdan a las de las FM [26]. Estos colaterales, según algunos autores, nunca abandonan la capa granular [23], pero podrían pasar a la capa molecular.

Lo más característico de estas células es la presencia de una única dendrita (Figs. 2b, 2c y 3) que al final de la misma presenta grupos de pequeños apéndices, a modo de cepillo, que dan nombre a estas células. La dendrita única tiene un diámetro de 2-3 $\mu \mathrm{m}$ y una longitud media de 10-30 $\mu \mathrm{m}$, aunque puede observarse con una longitud menor o, por el contrario, llegar a medir $50 \mu \mathrm{m}$ de longitud. Tiene un recorrido variable, puede ser recto o curvo, y apunta con la misma frecuencia hacia la capa molecular como a la sustancia blanca o a los laterales de la capa granular. Puede bifurcarse en forma de ' $\mathrm{T}$ ' en algunos casos

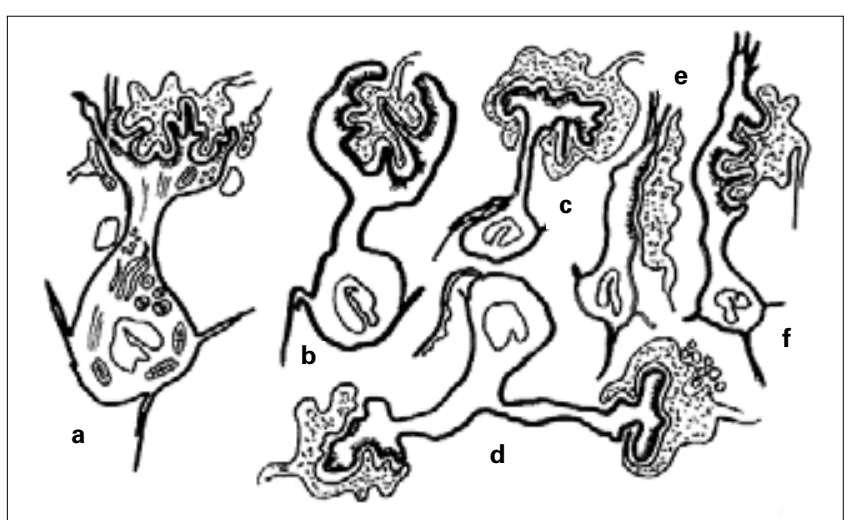

Figura 3. Tipos de CEC: a) Forma más convencional; b) Célula con terminal dendrítico englobando una fibra musgosa; c) Célula con terminal dendrítico en forma de seta; d) Célula con dendrita en ' $T$ '; e) Formación sináptica musgosa/troncodendrítica lineal; f) Formación sináptica musgosa/troncodendrítica interdigitada.

(Fig. 3d). La estructura terminal sobre la que asienta el cepillo puede tener una gran expansión de forma redondeada (Fig. 2a), ovoidal o, más frecuentemente, en forma de capuchón o de seta, de unos 10-30 mm de diámetro, que recubre o se engloba por uno o dos glomérulos sinápticos (Fig. 3).

Partiendo de la base de que ninguna inmunotinción es específica de estas células, inmunocitoquímicamente hablando se caracterizan por presentar una reactividad:

- Negativa para GABA y glicina -lo que permite distinguirlas de las células de Golgi, que son GABA y generalmente glicina positivas-; para las formas fosforiladas de neurofilamentos de alto peso molecular (NF-H), [28]; para distintos anticuerpos contra las distintas subunidades de los receptores de glutamato, como son los que reconocen sólo la subunidad GluR1 -en la mayoría de las CEC-, la subunidades GluR4, o la subunidad KA-2 y para anticuerpos que reconocen tanto a la subunidad GluR6 como GluR7 (Ab13-2), las subunidades NR1, NR2, NR3 y NR4, y las subunidades R2A y B [29].

- Positiva para proteínas fijadoras de calcio, especialmente calretinina -en la mayoría de las CEC-, que muestran una inmunopositividad muy superior a cualquier otro tipo de célula [18,20]; para la cromogranina A [15] y para la secretogranina II (o cromogranina C) [30]; para formas no fosforiladas de neurofilamentos de alto (NF-H), bajo (NF-L), y medio peso molecular (NF-M) [28]; para las secuencias repetidas de lisina-serina-prolina de la subunidad NF-H en su forma defosforilada (anticuerpo Rat-302) [31]; para alfainternexina; para la enzima óxido nítrico sintasa [32]. También son positivas para distintos anticuerpos de receptores de glutamato, que reconocen a la vez varias subunidades, como son las subunidades GluR2, GluR3 [23] y GluR4c, las subunidades GluR5, GluR6 y GluR7 [29]; y las subunidades NR1 y NR2 [29].

En el cerebelo, los resultados inmunocitoquímicos suelen ser bastante similares en todas las especies, pero en el núcleo coclear de los primates muchas de las células son calretinina negativas, y algunas, en cambio, son calbindina positivas [22]. Esto plantea la posible existencia de diferentes estirpes de CEC, que se ha intentado aclarar con estudios conjuntos morfológicos y de colocalización inmunohistoquímica. Aunque no existe toda- 
vía una definición totalmente aceptada de subtipos, el estudio de inmunorreactividad conjunta de calretinina con las distintas subunidades de los receptores del glutamato ha servido para definir dos clases distintas de CEC: células calretinina positivas/GluR1-alfa negativas, y células calretinina negativas/GluR1-alfa positivas, con distribuciones en el cerebelo, que se superponen parcialmente en el lóbulo $\mathrm{X}$ y con distintas formas de agruparse a través del eje mediolateral y dorsoventral de la folia [33].

\section{Características al microscopio electrónico}

La caracterización pormenorizada de estas células por microscopía electrónica (ME) fue realizada especialmente por Mugnaini et al en 1994 [34]. El núcleo de las CEC presenta cromatina dispersa y tiene profundas invaginaciones citoplásmicas que contienen numerosos polirribosomas, pero sin neurofilamentos. El citoplasma se caracteriza por presentar escasas formaciones de retículo endoplásmico rugoso, de forma bastante irregular, y aparato de Golgi prominente, situado en las proximidades del inicio de la dendrita o dentro de ella. Es rico en mitocondrias, microtúbulos y neurofilamentos, que apa-

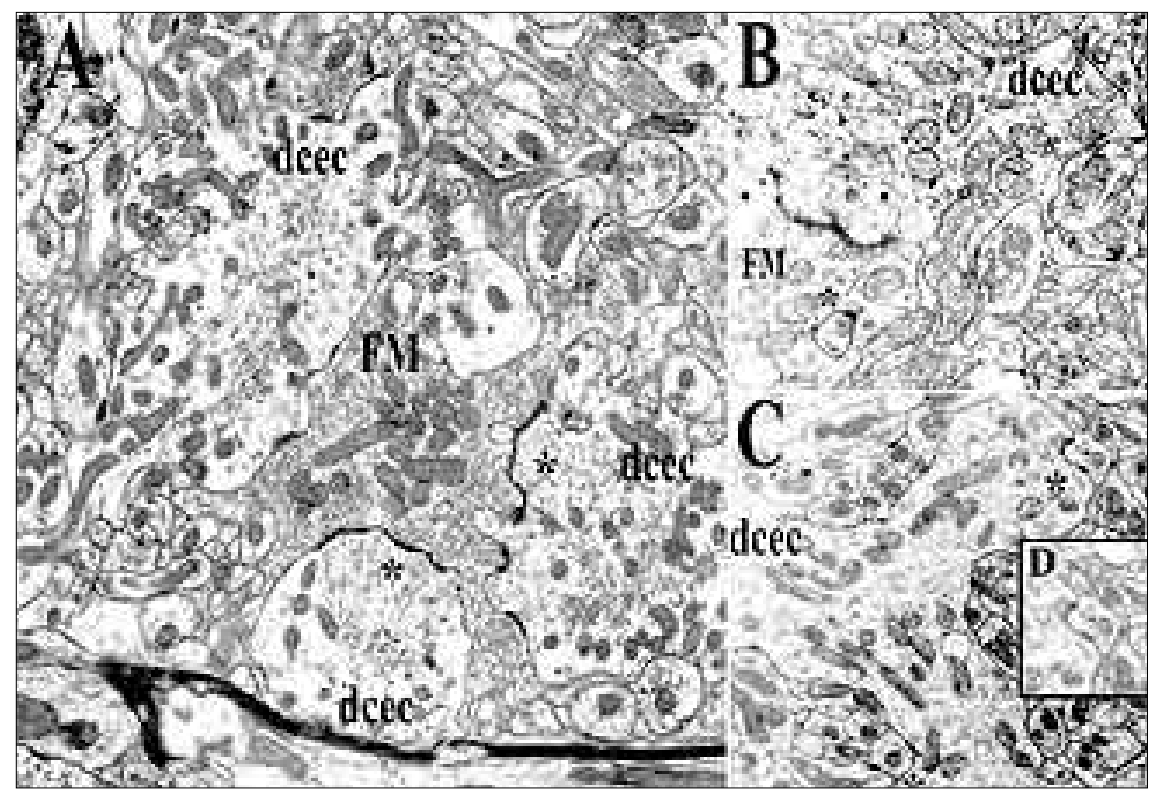

Figura 4. Cerebelo de rata, lóbulo VI: a) Se observa una fibra musgosa central (FM) rodeada por tres grandes protrusiones, y otras de menor tamaño, del terminal dendrítico de una CEC (dcec), que rodean la práctica totalidad de una FM. En los terminales dendríticos se puede observar gran cantidad de mitocondrias, microtúbulos y neurofilamentos. Los contactos sinápticos son de tipo asimétrico, de tamaño variable, la mayoría de ellos de gran longitud en su sección transversal (*); b) Terminal dendrítico de una CEC (dcec) que contacta a través de una placa sináptica única con una FM. Se puede observar la presencia de digitaciones finas $(\rightarrow)$ en los bordes del terminal (cepillo). También se observan finas digitaciones que penetran en el interior de la FM con la que hace sinapsis $\left({ }^{*}\right)$. En su citoplasma se pueden observar vesículas electrodensas, y cuerpos multivesiculares, además de gran cantidad de microtúbulos, mitocondrias; c) Tronco dendrítico que se bifurca en ' $T$ ' de una CEC rodeado por dendritas de las células grano. Se observan algunos contactos sinápticos dendrodendríticos con alguna dendrita de los granos $\left(^{*}\right)$. Las vesículas sinápticas se observan en la CEC cerca de la membrana; d) Detalle del contacto dendrodendrítico. recen solos o en haces (Fig. 4). Tanto los

neurofilamentos como los neurotúbulos son abundantes en el tronco dendrítico, pero no en la zona próxima a la sinapsis [35]. Una característica importante es la existencia de un número variable, pero importante, de grandes vesículas de contenido electrodenso, situadas en el soma, tronco dendrítico y apéndices (Fig. 4b). Ocasionalmente, aparecen grupos de vesículas redondas, pequeñas y claras, situadas en el citoplasma o en la dendrita cerca de la membrana (Fig. 4c), y que pueden interpretarse como zonas presinápticas. También existen diferentes tipos de cuerpos multivesiculares y algún cilio rudimentario [34].

En el soma, las células brush se caracterizan por presentar pequeños apéndices finos $(1 \times 3 \mu \mathrm{m})$, que varían en la forma y no establecen ningún tipo de sinapsis. Pueden contener algunos orgánulos citoplasmáticos, pero no neurofilamentos, ni microtúbulos. Estos apéndices son similares a los elementos del cepi1lo. El axón se recubre siempre por multitud de procesos astrocitarios [34]. Los axones colaterales son amielínicos y terminan en forma de roseta, de morfología similar al de las FM (Fig. 5) [27]. La estructura dendrítica forma una sinapsis gigante característica de estas células, y que se describe a continuación, junto a otros contactos sinápticos.

\section{Contactos sinápticos y posibles circuitos en los que se implican Contactos sinápticos (Figs. 3, 4 y 5)}

Aunque lo más llamativo de las CEC son las formaciones sinápticas gigantes del tronco dendrítico con la FM, también se establecen contactos sinápticos sencillos con células de Golgi, células grano e, incluso, con células de Lugaro y las propias CEC [36].
Las formaciones sinápticas CEC-musgosa son estructuras enormemente complejas y desarrolladas, semejantes a las sinapsis ‘en marrón' entre la FM y el soma de las células Golgi que describieron Palay y Chan-Palay [37] (Figs. 4a y 4b). Estas formaciones sinápticas se construyen sobre el terminal dendrítico celular o cepillo (Figs. 3a-d) y en alguna ocasión en el soma o en el tronco dendrítico (Figs. 3e-f). Cada terminal forma parte de un glomérulo o, a lo sumo, dos. Si la dendrita de la CEC se divide, puede formar parte de dos o más glomérulos distintos (Fig. 3d). Cada terminal dendrítico tiene protrusiones a modo de dedos, que se interdigitan en la FM y establecen sinapsis (Fig. 4b). Cuando la formación sináptica se establece en el extremo del tronco dendrítico, en algunos casos el terminal dendrítico cubre toda la superficie de la musgosa (Figs. 3b y $4 \mathrm{a}$ ), en otros se recubre por la musgosa (Figs. 3c y 3d) y en otras ocasiones se interdigitan prolongaciones de ambas estructuras. Se pueden observar siempre prolongaciones del cepillo, estrechas y sin sinapsis, que penetran en la musgosa. Los contactos sinápticos que se establecen son de tipo asimétrico y tienen tamaño y forma variable, desde las más pequeñas, similares a las sinapsis convencionales sobre las espinas dendríticas, hasta placas de más de $3 \mu \mathrm{m}$ de diámetro. La suma de las áreas sinápticas de una estructura de contacto CEC-musgosa puede llegar a ser de unas $40 \mu \mathrm{m}^{2}$ [34].

En los casos donde la FM se acopla al tronco dendrítico de la $\mathrm{CEC}$, se pueden producir o no interdigitaciones de protrusiones de ambas estructuras, y establecerse, en todos los casos, contactos sinápticos en placas grandes o en placas pequeñas seriadas de igual o distinto diámetro a las mencionadas. 


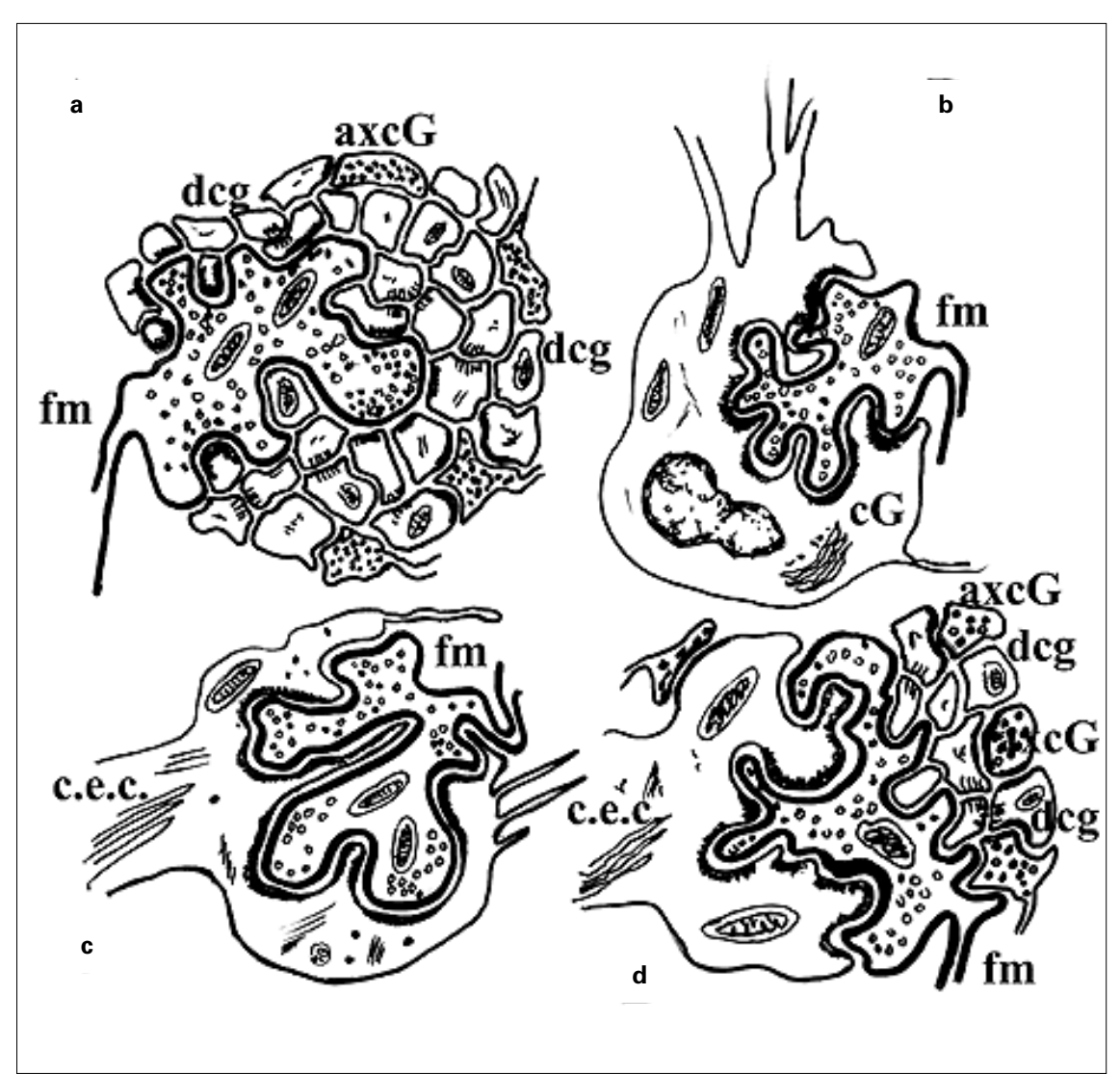

Figura 5. Tipos de formaciones sinápticas 'musgosas: a) Glomérulo convencional, que sinapta sobre terminal dendríticos de células de los granos. En la periferia se aprecian terminales inhibidores de los axones de las células de Golgi; b) Sinapsis 'en marrón' de una musgosa sobre el soma de una célula de Golgi; c) Sinapsis musgosa/CEC similar a la anterior, pero efectuado sobre la gran dendrita; d) Formación sináptica glomerular mixta en la que participa un terminal monodendrítico de CEC. Estas fibras 'musgosas' pueden ser terminales de verdaderas fibras musgosas extracelulares, colaterales de fibras trepadoras -en este caso suelen presentar mayor contenido de vesículas sinápticas [32]- o axones colaterales o terminales de CEC (axcG: axones de células de Golgi; dcg: dendrita de célula grano; cG: célula de Golgi; fm: fibra musgosa; CEC: célula en cepillo o monopolar).

Las FM que establecen sinapsis sobre las CEC podrían ser terminales de diferentes neuronas -extra o intracerebelosas (CEC)-, pero no se diferencian morfológicamente [38].

Aparte de esta estructura sináptica gigante, se observan otros contactos sinápticos que se producen en del soma y el tronco dendrítico:

- Con pequeños terminales axónicos de las células de Golgi: sinapsis de tipo simétrico, con vesículas sinápticas pleomórficas.

- Con dendritas de las células grano (Fig. 4c): estos contactos sinápticos son muy escasos, de tipo asimétrico, donde la CEC ejercería de elemento presináptico, ya que, como se dijo, se observan grupos de vesículas sinápticas redondas en las proximidades de la membrana de la CEC.

Los axones colaterales de las CEC en la capa granular están en contacto con las dendritas de las células grano, aunque no se han observado contactos sinápticos. No se aclara, sin embargo, el que las CEC formen glomérulos convencionales con dendritas de células grano. No se puede descartar la existencia de sinapsis eléctricas, ya que los espacios entre las membranas de los axones de las CEC y otras prolongaciones neuronales, en muchos casos parece muy reducida [39].
Hay que señalar que las pequeñas prolongaciones somáticas, así como las finas prolongaciones del cepillo, no reciben sinapsis. Algunos autores, como Yan y Garey, en 1996 [40], han sugerido que, además de las FM y otras células CEC, algunas monodendríticas podrían contactar con colaterales de fibras trepadoras que forman terminales musgosos en la capa de los granos.

\section{Circuitos (Fig. 1c)}

Las principales aferencias sinápticas excitadoras parecen ser las FM, mayoritariamente glutamatérgicas, que tienen su origen en el ganglio vestibular o en los núcleos vestibulares [41,42]. En las áreas donde la densidad de CEC es mayor, se ha observado la existencia de una pequeña población de FM colinérgicas, provenientes también de los núcleos vestibulares, que presumiblemente sinaptarán con las CEC [42,43].

Para otras CEC, las aferencias musgosas pueden ser colaterales de cualquiera de las neuronas que terminan en el cerebelo como musgosas, o incluso, de algunas fibras trepadoras [36]. También se ha descrito que colaterales, o terminales, axónicos de algunas CEC sinaptan con otras CEC, y se ha llegado a considerar que podría existir una cadena de neuronas CEC interconectadas para cumplir labores de coordinación de diversos módulos funcionales del cerebelo [9-14]. Una aferencia inhibitoria demostrada es la que proviene de las células de Golgi.

Las conexiones eferentes de las CEC, aparte de las producidas sobre otras CEC, parecen ser prioritarias hacia las neuronas de los núcleos vestibulares. Esta eferencia es corticoextracerebelosa directa. Se desconoce con exactitud si existen otras eferencias extracerebelosas o conexiones con los núcleos cerebelosos centrales. Dentro de la corteza se establecen conexiones eferentes con las dendritas de algunas células grano, pero todavía no se ha demostrado la conexión masiva que se produciría si existieran 'glomérulos cerebelosos' en los que la musgosa fuera el axón de una CEC.

En la figura 1c se pueden observar los posibles circuitos en los que intervienen las CEC dentro del esquema básico del cerebelo.

\section{Variaciones fisiológicas y patológicas Variaciones fisiológicas}

Son pocos todavía los trabajos que estudian las variaciones de las CEC, a lo largo del desarrollo ontogénico, y muchos menos los relativos a la posible involución durante el envejecimiento fisiológico que afectan a todo el sistema nervioso central (SNC) o, específicamente, al cerebelo.

Los diferentes autores que han estudiado la evolución de las células calretinina positivas durante el desarrollo ontogénico del cerebelo han mostrado que existen marcadas diferencias en función de la especie. Por ejemplo, en el ratón se observó que hacia 
el período embrionario E12 aparecen las primeras células y fibras, ligeramente teñidas, en la zona media del cerebelo. Entre el período E14 y E16, las células aparecen en la porción dorsocaudal de la capa germinal externa del cerebelo y migran rostroventralmente. Algunas células parecen ser células pálidas o CEC. En E18, abundantes células positivas se localizan ventralmente en la comisura cerebelosa, así como en la parte más lateral del cerebelo, cuyo destino será los flóculos y paraflóculos, mientras que las células más ventrales se incorporarán al lóbulo noduloflocular. Después del período embrionario, en el cerebelo hay pocos cambios. En el P0, desde el área caudal del cerebelo, las células CEC que muestran largos procesos, migran dorso y ventrolateralmente a la región en desarrollo del paraflóculo. Durante los días P3 y P4, el lóbulo ansiforme contiene el mayor número de células CEC, aunque éstas se detectan también en otros lóbulos, como en el lóbulo VIII, donde se localizan rostrolateralmente [44]. Este desarrollo fue muy similar al de la rata [45], donde además se estudió la maduración de las sinapsis entre las células brush y las FM. El cepillo se diferencia durante los 21 días posnatales (P2-P21), y la longitud media de la sinapsis crece a medida que aumenta la diferenciación del cepillo [38]. Sin embargo, los estudios en gatos [46] han mostrado que en el primer día posnatal P0, sólo se detectan CEC en la sustancia blanca del lóbulo X vermal. A partir del día P8, las CEC invaden la sustancia blanca y la capa granular interna de los lóbulos vermales IX, VIII, I y II, y se sitúan en la zona intermedia entre el vermis y los hemisferios. A partir del día P12, se encuentran células CEC en los lóbulos III y VII del vermis y los lóbulos laterales correspondientes del neocerebelo, y empiezan a invadir los lóbulos V y VI. La migración medial-lateral y la incorporación de células CEC en los lóbulos V y VI sólo se completa hacia el día P132, y la distribución que se alcanza en este momento es la misma que en gatos adultos de un año. Sin embargo, la migración celular continúa hasta los cuatro meses.

Los estudios en humanos escasean mucho, aunque se ha mostrado que las CEC calretinina positivas se detectan hacia la semana 21 de gestación, donde aparecen inmunoteñidas también células de Purkinje, células cesto y neuronas del núcleo dentado. Tanto el número como la intensidad de la inmunotinción aumentan a medida que el cerebelo madura [47].

Sólo se ha encontrado un trabajo donde se estudia la variación de las células calretinina positivas en el envejecimiento fisiológico de los hámsteres, por medio de hibridación in situ, y no se observa ningún cambio [48]. Con anterioridad, se había considerado que las 'células pálidas' de los roedores no disminuían con la edad [49].

\section{Variaciones patológicas}

De igual forma, existen pocos estudios sobre las CEC en situaciones patológicas. En la enfermedad de Pick se demostró, que en algunos casos, las CEC se afectan [50]. Los resultados de estudios realizados sobre células calretinina positivas, en general, en otras áreas cerebrales, como el hipocampo, la corteza entorrinal, temporal y visual, en enfermos de Alzheimer, han mostrado que estas células son relativamente resistentes a la degeneración [51-54], pero no existen análisis en el cerebelo. En la actualidad nuestro equipo lleva a cabo un estudio de estas células, para analizar su resistencia a la neurodegeneración.

\section{Consideraciones 'provisionales'sobre las CEC del cerebelo}

Todavía no se conoce bien cuál es el papel fisiológico de este tipo celular o tipos celulares. Tampoco se conoce su número exacto, ni sus relaciones completas con el resto de los circuitos cerebelosos. Su aparente pequeño número respecto al de otros tipos celulares del cerebelo y su escaso número de interrelaciones neuronales, no tiene por que significar una función menos importante. En algunas regiones, como los lóbulos I y X, su número es similar al de las células Golgi de pequeño tamaño, y es posible que no sea mayor la abundancia de sinapsis 'en marrón' (FM-soma de la célula de Golgi) que la de sinapsis establecidas entre FM-CEC. Los aspectos que consideramos de mayor relevancia en estas células, y en los principales circuitos que forman, son:

- Existencia de un nuevo sistema eferente de la corteza cerebelosa de posible carácter excitatorio. Hasta el momento, y desde las descripciones de Cajal [1], se considera que la única eferencia de la corteza cerebelosa era el axón de la célula de Purkinje y que, como se demostró posteriormente, es gabérgica inhibidora. En este sentido, la compleja red de circuitos corticales es únicamente un sistema de regulación inhibitoria de los núcleos cerebelosos centrales que reciben el estímulo aferente por las denominadas antiguamente 'colaterales' de las FM y trepadoras -que funcionalmente deben considerarse las terminaciones principales que excitan las neuronas de salida de impulsos del cerebelo-. Los axones de algunas CEC son una nueva eferencia cortical y podrían excitar directamente neuronas extracerebelosas del núcleo vestibular, y formar una realimentación positiva, cuya función sería la de aumentar la duración y la intensidad de las órdenes vestibulocoliculares, vestibulooculares e incluso cardiorrespiratorias con la utilización de este looplargo que pasa por las CEC [27]. Esto se apoyaría por el hecho de que las CEC presentan una mayor densidad en aquellas regiones que se implican en funciones motoras, visuales y posturales, e influyen en el control de los movimientos y ajustes posturales que dependen de estímulos propioceptivos, oculares y vestibulares [18,20,55,56]. Posiblemente, otras CEC situadas en el neocerebelo podrían acabar en otros núcleos cerebrales.

- Existencia de un conjunto de nuevos modelos de circuitos cerebelosos. La corteza cerebelosa es el mejor ejemplo de convergencia y divergencia de impulsos, y se forman redes muy tupidas, donde se expanden los impulsos de una neurona a miles de células (terminal en musgosa/célula grano) y donde algunas neuronas reciben miles de conexiones procedentes de otras neuronas (célula de Purkinje/células grano) (Fig. 1). Sin embargo, las CEC parecen tener una conexión lineal FM-CEC que no sólo puede salir directamente al exterior (núcleos vestibulares), sino que puede dar lugar a una cadena lineal -varias CEC encadenadas- o formar fibras trepadoras. Estos distintos circuitos morfofuncionales pueden ser básicos para la regulación de diferentes unidades funcionales del cerebelo. Daños en estos circuitos podrían alterar gravemente la función del cerebelo.

- Ampliación del nuevo modelo de macrosinapsis mononeuronal descrito por Palay (o sinapsis 'en marrón', establecida entre la FM y el soma de la célula de Golgi). En muchos cortes histológicos, estudiados aisladamente, cuando no se observa indentación de la musgosa cerca de la región perinuclear de las células de Golgi, es difícil distinguir las sinapsis sobre las células de Golgi y sobre las CEC. En algunas regiones del cerebelo de los peces encontramos, hace años, glomérulos 'paucidendríticos' de FM sobre grandes dendritas de dos o tres células grano, o neuronas de otro tipo que fue imposible tipificar, sin 
que pudiera describirse el circuito que formaban [57]. También se encontraron sinapsis de este tipo sobre grandes troncos dendríticos de células grano, que se interpretaron como primordios de los glomérulos que en peces se siguen formando a lo largo de toda la vida [58]. Con estos nuevos datos, este tipo de sinapsis parece que es frecuente en el cerebelo y que puede tener distintas funciones en el desarrollo y en la etapa adulto.

- Posible existencia de un sistema neurosecretor en el cerebelo. Comúnmente, las vesículas electrodensas se asocian a neuropéptidos, y su presencia en número elevado en el citoplasma se asocia a una función neurosecretora. Ya que las CEC presentan estos orgánulos, podría pensarse en una función secretora de estas células.
- Confirmación de la existencia de 'módulos funcionales' en el cerebelo. Quizás estas neuronas controlen dentro de la corteza cerebelosa 'módulos' morfofuncionales, de naturaleza todavía desconocida, pero que ya se observan tras la tipificación inmunocitoquímica [9-14]. Estos módulos pueden ser imprescindibles para la cada vez más amplia gama de funciones cognitivas que se asignan al cerebelo [2-8].

Esperamos que nuevos estudios de estas células, dirigidos al análisis de sus circuitos, así como al de sus alteraciones en distintas condiciones patológicas y modelos experimentales, nos ayuden a aclarar su papel en el cerebelo.

\section{BIBLIOGRAFÍA}

1. Ramón y Cajal S. Histologie du système nerveux de l'homme et des vertébrés. Vol 2. Paris: Maloine; 1911.

2. Fiez JA. Cerebellar contributions to cognition. Neuron 1996; 16: 13-5.

3. Raymond JL, Lisberger SG, Mauk MD. The cerebellum: a neuronal learning machine. Science 1996; 272: 1126-31.

4. Delgado JM. Estructura y función del cerebelo. Rev Neurol 2001; 33: 635-42.

5. Ito M. Mechamisms of motor learning in the cerebellum. Brain Res 2000; 886: 237-45

6. Montag-Sallaz M, Montag D. Severe cognitive and motor coordination deficits in tenascin-R-deficient mice. Genes Brain Behav 2003; 2: 20-31.

7. Claeys KG, Orban GA, Dupont P, Sunaert S, Hecke PV, Schutter ED. Involvement of multiple functionally distinct cerebellar regions in visual discrimination: a human functional imaging study. Neuroimage 2003; 20: 840-54.

8. Gottwald B, Mihajlovic Z, Wilde B, Mehdorn HM. Does the cerebellum contribute to specific aspects of attention? Neuropsychologia 2003; 41: 1452-60.

9. Imamizu H, Kuroda T, Miyauchi S, Yoshioka T, Kawato M. Modular organization of internal models of tools in the human cerebellum. Proc Natl Acad Sci USA 2003; 100: 5461-6.

10. Voogd J, Pardoe J, Ruigrok TJ, Apps R. The distribution of climbing and mossy fiber collateral branches from the copula pyramidis and the paramedian lobule: congruence of climbing fiber cortical zones and the pattern of zebrin banding within the rat cerebellum. J Neurosci 2003; 23: 4645-56.

11. Sillitoe RV, Hulliger M, Dyck R, Hawkes R. Antigenic compartmentation of the cat cerebellar cortex. Brain Res 2003; 977: 1-15.

12. Jinno S, Jeromin A, Roder J, Kosaka T. Compartmentation of the mouse cerebellar cortex by neuronal calcium sensor-1. J Comp Neurol 2003; 458: 412-24.

13. Singec I, Knoth R, Ditter M, Frotscher M, Volk B. Neurogranin expression by cerebellar neurons in rodents and non-human primates. J Comp Neurol 2003; 459: 278-89.

14. MacLeod CE, Zilles K, Schleicher A, Rilling JK, Gibson KR. Expansion of the neocerebellum in Hominoidea. J Hum Evol 2003; 44: 401-29.

15. Munoz DG. Monodendritic neurones: a cell type in the human cerebellar cortex identified by chromatogranin A-like inmunoreactivity. Brain Res 1977; 528: 335-8.

16. Mugnaini E, Floris A. The unipolar brush cell: a neglected neuron of the mammalian cerebellar cortex. J Comp Neurol 1994; 339: 174-80.

17. Atlman J, Bayer SA. Time of origin and distribution of new cell type in the rat cerebellar cortex. Exp Brain Res 1977; 29: 265-74.

18. Floris A, Dunn ME, Berrebi AS, Jacobowitz DM, Mugnaini E. Pale cells of the flocculonodular lobe are calretinin positive. Soc Neurosci Abstr 1992; 18: 853.

19. Floris A, Diño M, Jacobowitz DM, Mugnaini E. The unipolar brush cells of the rat cerebellar cortex and cochlear nucleus are calretininpositive: a study by light and electron microscopic immunocytochemistry. Anat Embryol (Berl) 1994; 189: 495-520.

20. Braak E, Braak H. The new monodendritic neuronal type within the adult human cerebellar granule cell layer shows calretinin-inmunoreactivity. Neuroscience letters 1993; 154: 199-202.

21. Wright DD, Blackstone CD, Huganir RL, Ryugo DK. Immunocytochemical localization of the mGluR1 alpha metabotropic glutamate receptor in the dorsal cochlear nucleus. J Comp Neurol 1996; 364: 729-45.

22. Spatz WB. Unipolar brush cells in the cochlear nuclei of a primate (Callithrix jacchus). Neurosci Lett 1999; 270: 141-4.
23. Spatz WB. Unipolar brush cells in marmoset cerebellum and cochlear nuclei express calbindin. Neuroreport 2000; 11: 1-4.

24. Spatz WB. Unipolar brush cells in the human cochlear nuclei identified by their expression of a metabotropic glutamate receptor (mGluR2/3). Neurosci Lett 2001; 316: 161-4.

25. Diño MR, Willard FH, Mugnaini E. Distribution of unipolar brush cells and other calretinin immunoreactive components in the mammalian cerebellar cortex. J Neurocytol 1999; 28: 99-123.

26. Rossi DJ, Alford S, Mugnaini E, Slater NT. Properties of transmission at a giant glutamatergic synapse in cerebellum: the mossy fiber-unipolar brush cell synapse. J Neurophysiol 1995; 74: 24-42.

27. Berthie B, Axelrad H. Granular layer collaterals of the unipolar brush cell axon display rosette-like excrescences. A Golgi study in the rat cerebellar cortex. Neurosci Lett 1994; 167: 161-5.

28. Harris J, Moreno S, Shaw G, Mugnaini E. Unusual neurofilament composition in cerebellar unipolar brush neurons. J Neurocytol 1993; 22: 1039-59.

29. Jaarsma D, Wenthold RJ, Mugnaini E. Glutamate receptor subunits at mossy fiber-unipolar brush cell synapses: light and electron microscopic immunocytochemical study in cerebellar cortex of rat and cat. J Comp Neurol. 1995; 357: 145-60.

30. Cozzi MG, Rosa P, Greco A, Hille A, Hüttner WB, Zanini A, et al. Immunohistochemical localization of secretograminin II in the rat cerebellum. Neuroscience 1989; 28: 423-41.

31. Hockfield SA. Map to a unique cerebellar neuron generated by immunosuppression and rapid immunization. Science 1987; 237: 67-70.

32. Kitahara T, Takeda N, Emson PC, Kubo T, Kiyama H. Changes in nitric oxide synthase-like immunoreactivities in unipolar brush cells in the rat cerebellar flocculus after unilateral labyrinthectomy. Brain Res 1997; 765: 1-6.

33. Nunzi MG, Shigemoto R, Mugnaini E. Differential expression of calretinin and metabotropic glutamate receptor mGluRlalpha defines subsets of unipolar brush cells in mouse cerebellum. J Comp Neurol 2002; 451: 189-99.

34. Mugnaini E, Floris A, Wright-Goss M. Extraordinary synapses of the unipolar brush cell: an electron microscopic study in the rat cerebellum. Synapse 1994; 16: 284-311.

35. Diño MR, Mugnaini E. Postsynaptic actin filaments at the giant mossy fiber-unipolar brush cell synapse. Synapse 2000; 38: 499-510.

36. Melik-Musian AB, Fanarjan VV. Structural organization and Lugaro neuron connections in the cat cerebellar cortex. Morfologia 1998; 113: 44-8.

37. Palay SL, Chan-Palay V. Cerebellar Cortex: cytology and organization. New York: Springer-Verlag; 1974.

38. Diño MR, Perachio AA, Mugnaini E. Cerebellar unipolar brush cells are targets of primary vestibular afferents: an experimental study in the gerbil. Exp Brain Res 2001; 140: 162-70.

39. Axelrad H, Korn H. Field effect and chemical transmission: dual inhibitory action of basket cells in the rat cerebellar cortex. In Palay SL, Chan-Palay V, eds. The cerebellum. New Vistas. Berlin: SpringerVerlag; 1982. p. 412-29.

40. Yan XX, Garey LJ. Calretinin immunoreactivity in the monkey and cat cerebellum: cellular localization and modular distribution. J Hirnforsch 1996; 37: 409-19.

41. Nunzi MG, Birnstiel S, Bhattacharyya BJ, Slater NT, Mugnaini E. Unipolar brush cells form a glutamatergic projection system within the mouse cerebellar cortex. J Comp Neurol 2001; 434: 329-41.

42. Barmack NH, Baughman RW, Eckenstein FP. Cholinergic innervation of the cerebellum of the rat, rabbit, cat, and monkeys as revealed by 
choline acetyltransferase immunocitochemistry, retrograde and orthograde tracer. J Comp Neurol 1992; 317: 250-70.

43. Jaarsma D, Dino MR, Cozzari C, Mugnaini E. Cerebellar choline acetyltransferase positive mossy fibres and their granule and unipolar brush cell targets: a model for central cholinergic nicotinic neurotransmission. J Neurocytol 1996; 25: 829-42.

44. Abbott LC, Jacobowitz DM. Development of calretinin-immunoreactive unipolar brush-like cells and an afferent pathway to the embryonic and early postnatal mouse cerebellum. Anat Embryol (Berl) 1995; 191: 541-59.

45. Morin F, Dino MR, Mugnaini E. Postnatal differentiation of unipolar brush cells and mossy fiber-unipolar brush cell synapses in rat cerebellum. Neuroscience 2001; 104: 1127-39.

46. Takacs J, Borostyankoi ZA, Veisenberger E, Vastagh C, Vig J, Gorcs TJ, et al. Postnatal development of unipolar brush cells in the cerebellar cortex of cat. J Neurosci Res 2000; 61: 107-15.

47. Yew DT, Luo CB, Heizmann CW, Chan WY. Differential expression of calretinin, calbindin D28K and parvalbumin in the developing human cerebellum. Brain Res Dev Brain Res 1997; 103: 37-45.

48. Kishimoto J, Tsuchiya T, Cox H, Emson PC, Nakayama Y. Age-related changes of calbindin-D28K, calretinin and parvalbumin mRNAs in the hamster brain. Neurobiol Aging 1998; 19: 77-82.

49. Sturrok RR A quantitative histological study of Golgi II neurons and pale cells in different cerebellar regions on the adult and aging mouse brain. Z Mikrosk Anat Frosch 1999; 104: 705-10.

50. Braak E, Arai K, Braak H. Cerebellar involvement in Pick's disease:

\section{NUEVA CÉLULA 'EN CEPILLO'(BRUSH CELL) \\ O CÉLULA MONOPOLAR DEL CEREBELO. CARACTERÍSTICAS Y POSIBLE FUNCIÓN}

Resumen. La estructura del cerebelo y los circuitos que forman sus neuronas se conocen muy bien desde la época de Cajal. En los últimos años se ha descrito un cierto número de nuevas conexiones neuronales y subtipos neuronales, así como compartimentos funcionales mediante técnicas inmunohistoquímicas. Esta nueva concepción morfofuncional del cerebelo se corresponde con las nuevas funciones que se le asignan en aprendizaje y memoria. Dentro de este esquema puede ser clave una nueva célula, mencionada por Altman y Bayer (1977) y descrita por Mugnaini (1994), la célula 'en cepillo', monopolar o monodendrítica, específica de la corteza cerebelosa -junto a los núcleos cocleares-, que presenta en todas las especies, incluido el hombre, morfología, reacción inmunohistoquímica (anticalretinina, receptores para glutamato, neurofilamentos, etc.) y conexiones muy características. La formación de una sinapsis gigante con una fibra musgosa es su principal aferencia, y posee o puede poseer terminales extracerebelosos directos, intracorticales -sobre otras células en cepillo en forma de terminal musgosa, o sobre otras neuronas-. En cada especie animal tiene un desarrollo diferente y parece que no involucionan ni en la senilidad ni en las enfermedades neurodegenerativas [REV NEUROL 2004; 38: 339-346]

Palabras clave. Calretinina. Células brush. Células en cepillo. Células monopolares. Células pálidas. Cerebelo. affliction of mossy fibers, monodendritic brush cells, and dentate projection neurons. Exp Neurol 1999; 159: 153-63.

51. Hof PR, Nimchinsky EA, Celio MR, Bouras C, Morrison JH. Calretinin-immunoreactive neocortical interneurons are unaffected in Alzheimer's disease. Neurosci Let 1993; 152: 145-8.

52. Fonseca M, Soriano E. Calretinin-immunoreactive neurons in the normal temporal cortex and in Alzheimer's disease. Brain Res 1995; 691: 83-91.

53. Pike CJ, Cotman CW. Calretinin-immunoreactive neurons are resistant to beta-amyloid toxicity in vitro. Brain Res $1995 ; 671: 293-8$.

54. Leuba G, Kraftsik R, Saini K. Quantitative distribucition of parvalbumin, calretinin, and calbindin D-28K immunoreactive neurons in the visual cortex of normal and Alzheimer cases. Exp Neurol 1998; 152: 278-91.

55. Noda H. Cerebellar control of saccadic eye movements: its neural mechanisms and pathways. Jpn J Physiol 1991; 41: 351-68.

56. Takacs J, Markova L, Borostyankoi Z, Gorcs TJ, Hamori J. Metabotrop glutamate receptor type 1a expressing unipolar brush cells in the cerebellar cortex of different species: a comparative quantitative study. J Neurosci Res 1999; 55: 733-48.

57. Carrato A, Toledano A, Barca MA. Postnatal development of astrocytic glia in the cerebellum of Cyprinus carpio. Prog Clin Biol Res 1981; 59: 37-43.

58. Toledano A. Cajal's studies on developing cerebellum. Their relations to modern finding on postnatal cerebellar circuitry. In Grisolia S, Guerri C, Sanson R, Norton R, Reinoso-Suárez F, eds. Ramon y Cajal's contribution to the Neurosciences. Amsterdam: Elsevier Science; 1983. p. $125-35$.

\section{NOVA CÉLULA 'EM ESCOVA' (BRUSH CELL) OU CÉLULA MONOPOLAR DO CEREBELO. CARACTERÍSTICAS E POSSÍVEL FUNÇÃO}

Resumo. A estrutura do cerebelo e os circuitos que formam os seus neurónios são muito bem conhecidos desde a época de Cajal. Nos últimos anos descreveu-se um certo número de novas conexões neuronais e subtipos neuronais, assim como compartimentos funcionais mediante técnicas imunohistoquímicas. Esta nova concepção morfofuncional do cerebelo tem correspondência com as novas funções que se lhe atribuem na aprendizagem e na memória. Dentro deste esquema pode ser chave uma nova célula, mencionada por Altman e Bayer (1977) e descrita por Mugnaini (1994), a célula 'em escova', monopolar ou monodendrítica, específica do córtex cerebeloso -junto aos núcleos cocleares-, presente em todas as espécies, inclusive no homem, morfologia, reacção imunohistoquímica (anticalretinina, receptores para glutamato, neurofilamentos, etc.) e conexões muito características. A formação de uma sinapse gigante com uma fibra musgosa é a sua principal aferência e possui, ou pode possuir, terminais extracerebelosos directos, intracorticais -sobre outras células em escova em forma de terminal musgosa, ou sobre outros neurónios-. Em cada espécie animal tem um desenvolvimento diferente e parece que não involucionam nem na senilidade nem nas doenças neurodegenerativas. [REV NEUROL 2004; 38: 339-346]

Palavras chave. Calretinina. Células em escova. Brush cells. Células monopolares. Células pálidas. Cerebelo. 